\title{
Cerebral Microbleeds: Their Associated Factors, Radiologic Findings, and Clinical Implications
}

\author{
Beom Joon Kim, ${ }^{a}$ Seung-Hoon Lee ${ }^{\mathrm{b}}$ \\ ${ }^{a}$ Department of Neurology and Cerebrovascular Center, Seoul National University Bundang Hospital, Seongnam, Korea \\ ${ }^{\mathrm{b}}$ Department of Neurology, Seoul National University Hospital, Seoul, Korea
}

Cerebral microbleeds (CMBs) are tiny, round dark-signal lesions that are most often detected on gradient-echo MR images. CMBs consist of extravasations of blood components through fragile microvascular walls characterized by lipohyalinosis and surrounding macrophages. The prevalence of CMBs in elderly subjects with no history of cerebrovascular disease is around 5\%, but is much higher in patients with ischemic or hemorrhagic stroke. Development of CMBs is closely related to various vascular risk factors; in particular, lobar CMBs are thought to be associated with cerebral amyloid angiopathy. The presence of CMBs has been hypothesized to reflect cerebral-hemorrhage-prone status in patients with hypertension or amyloid microangiopathy. Stroke survivors with CMBs have been consistently found to have an elevated risk of subsequent hemorrhagic stroke or an antithrombotic-related hemorrhagic complication, although studies have failed to establish a link between CMBs and hemorrhagic transformation after thrombolytic treatment. A large prospective study is required to clarify the clinical significance of CMBs and their utility in a decision-making index.

Keywords Cerebral microbleed; Ischemic stroke; Intracerebral hemorrhage; Antithrombotics; Gradient-echo MRI

\author{
Correspondence: Seung-Hoon Lee \\ Department of Neurology, Seoul National \\ University Hospital, 101 Daehak-ro, \\ Jongno-gu, Seoul 110-744, Korea \\ Tel: +82-2-2072-1014 \\ Fax: +82-2-3672-7553 \\ E-mail: sb0516@snu.ac.kr
}

Received: July 28, 2013

Revised: August 29, 2013

Accepted: September 9, 2013

The authors have no financial conflicts of interest.

\section{Introduction}

The term cerebral microbleed (CMB) refers to small, round dark-signal lesions detected by $\mathrm{T} 2{ }^{*}$-weighted or gradient-echo (GRE) magnetic resonance imaging (MRI). ${ }^{1} \mathrm{CMBs}$ were introduced to stroke physicians in the late 1990s and early 2000s after development of MRI techniques sensitive to paramagnetic effects. ${ }^{2}$ The clinical significance of CMBs has been actively investigated, especially in the stroke field and more recently in studies on cognitive impairment and aging. ${ }^{3}$ Histological investigation has shown that $\mathrm{CMBs}$ are tiny foci containing hemosiderin-laden macrophages and abnormal microvessels showing fibrohyalinosis. ${ }^{4,5}$ Clinical cases with frank symptoms caused by CMBs are uncommon. Because CMBs are manifestations of fo- cal extravascular leakage of blood components, however, investigators have suggested that accumulation of CMBs reflects a bleeding-prone status in individuals with an elevated risk of cerebral hemorrhage. Clinical studies have found strong associations between CMBs and chronic hypertension and low cholesterol levels, ${ }^{6,7}$ and between the proximity and volume of CMBs and those of subsequent intracerebral hemorrhage (ICH) ${ }^{8,9}$ Longitudinal studies have found that CMBs are linked to subsequent hemorrhagic stroke in stroke survivors, ${ }^{10}$ and suggested that $\mathrm{CMBs}$ are related to antithrombotic-related hemorrhage. ${ }^{11,12}$ In this review, we discuss fundamental findings of CMBs, and the clinical implications of these observations for the field of cerebrovascular disease. 


\section{Visualization and detection of cerebral microbleeds}

GRE sequences are more sensitive to susceptibility effects than are classical MRI sequences. Unlike classical T2-weighted imaging or echo-planar sequences, GRE sequences maximize the paramagnetic effects of blood components such as hemosiderin, deoxyhemoglobin, and ferritin. ${ }^{2,13}$ Due to the dephasing of MRI signals, GRE sequences tend to exaggerate lesion sizes. Therefore, sub-millimeter CMBs appear as signal-loss lesions of several millimeters, a phenomenon referred to as the blooming effect.

Susceptibility-weighted imaging (SWI) is a MRI sequence that maximizes sensitivity to magnetic susceptibility effects. ${ }^{14,15}$ SWI requires more time than does GRE, and also requires postprocessing, but because SWI accentuates the magnetic properties of tissues, it enables visualization of areas such as CMBs containing deoxygenated blood substances. ${ }^{16}$ SWI permits visualization of a greater number of CMBs than can be seen with conventional GRE sequences, but the clinical implications of this increased sensitivity are not yet fully understood (Figure 1). ${ }^{17}$

Since CMBs are primarily a radiologic concept, their sizes and shapes are dependent upon the parameters of the GRE sequence. Visualization of CMBs is thought to be influenced by pulse sequence, sequence parameters, spatial resolution, mag-

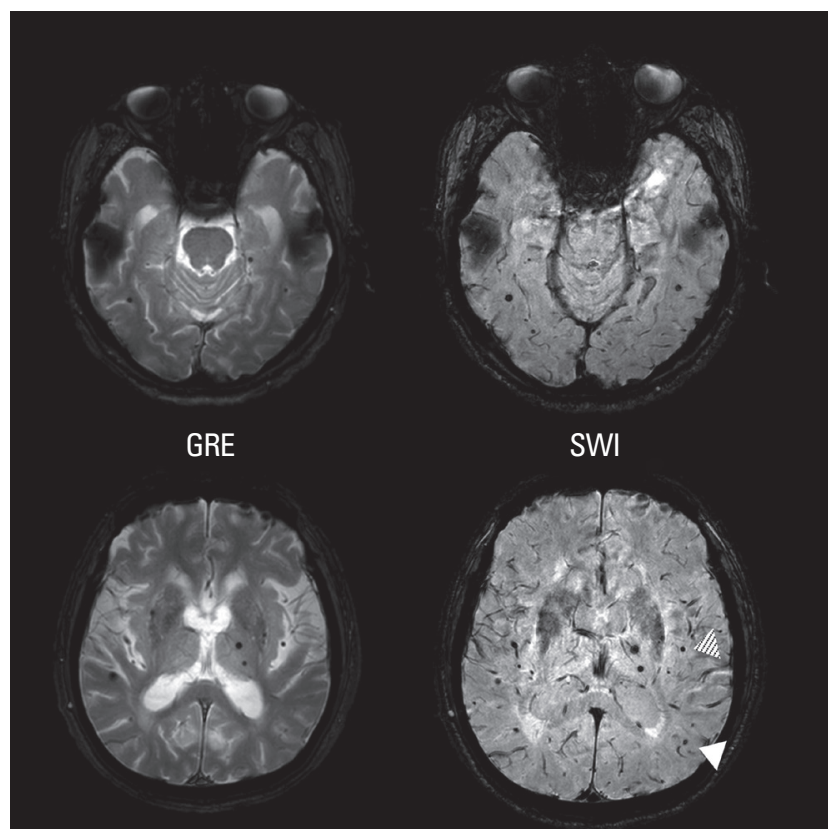

Figure 1. Cerebral microbleeds (CMBs) visualized on gradient-echo (GRE) images and susceptibility-weighted images (SWI). A lobar CMB on a SWI image (white arrow) is only faintly visible on the corresponding GRE image. Vessels located in the subarachnoid space could be mistakenly identified as CMBs on SWI sequence (hatched arrows). netic field strength, and post-processing of images. ${ }^{1}$ Thus, lesions due to old parenchymal hemorrhage, cortical or deep-seated mineralizations, or vascular malformations potentially all can be misinterpreted as CMBs. Small cortical vessels, partial volume effects of the cerebellar cortex, and cavernous hemangiomas also should be considered (Figure 2). ${ }^{21}$ Moreover, multifocal bleeding spots caused by diffuse axonal injury are virtually impossible to distinguish from cortico-subcortical CMBs.

Comparison of magnetic field strength in detection of CMBs revealed 0.5 more microbleeds on average could be observed using a 3.0 Tesla MRI compared to a 1.5 Tesla unit $(2.1$ in $3.0 \mathrm{~T}$ and 1.6 in $1.5 \mathrm{~T}) .{ }^{18}$ No universal standard MR parameters exist for the detection of CMBs, and in addition, the definition of $\mathrm{CMB}$ size also varies. In published reports, the lower limit of CMB size is usually $\leq 2 \mathrm{~mm}$, and the upper limit is usually between 5 and $10 \mathrm{~mm} .{ }^{19}$ Greenberg et al. reported that the size distribution of microbleeds and macrobleeds is bimodal, and proposed that the most appropriate cut-off point between them is $5.7 \mathrm{~mm} .{ }^{20}$ Those researchers suggested elsewhere that an upper size limitation is impractical, and that instead, a more desirable approach is to carefully exclude CMB-mimicking lesions such as those described above. ${ }^{1}$ Other investigators have proposed a specified rating scale for CMBs, the Microbleed Anatomical Rating Scale. ${ }^{21}$ In our view, setting an appropriate upper-size limitation, and determination of intra- and inter-rater

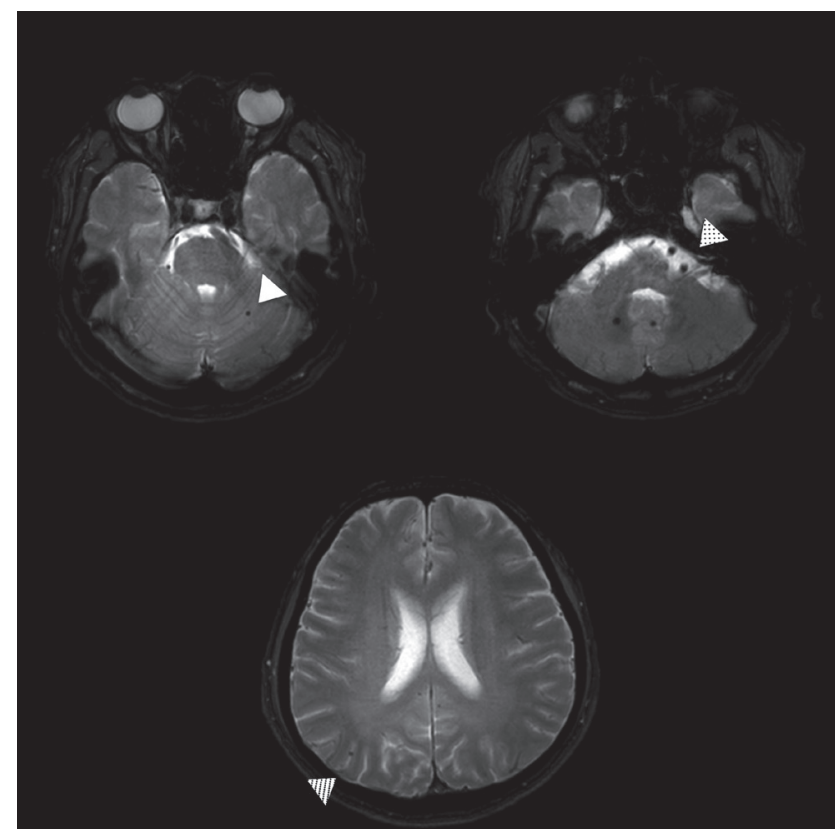

Figure 2. Cerebellar microbleeds (CMBs; white arrow). Two vertebral arteries in the subarachnoid space look similar to microbleeds (dotted arrow). One vessel signal located inside of a sulcus could be mistakenly interpreted as a CMB (hatched arrow). 
agreement values, are necessary for clinical and radiologic research studies.

\section{Pathology of cerebral microbleeds}

Pathologic-radiologic correlation studies have revealed that CMBs are focal accumulations of hemosiderin adjacent to abnormal blood vessels demonstrating fibrolipohyalinosis or amyloid microangiopathy. ${ }^{4,5} \mathrm{CMBs}$ usually develop adjacent to capillaries, small arteries, or arterioles; hemosiderin-laden macrophages are usually present. ${ }^{22} \mathrm{~A}$ recent pathological investigation of CMBs in patients with cerebral amyloid angiopathy demonstrated extravasation of blood and hemosiderin through vulnerable vascular walls, with $\beta$-amyloid pigmentation and surrounding inflammation. ${ }^{23}$ These findings suggest that $\mathrm{CMBs}$ are the radiologic correlates of extravasation of blood components through injured or fragile vascular walls, or of frank small hemorrhage spots. In the context of cerebral amyloid angiopathy, Greenberg et al. suggested that increased vascular wall thickness was indicative of microbleeds. ${ }^{20}$

Because blooming artifact on GRE images exaggerates the size of CMBs, it has been proposed that the actual size of hemosiderin deposition is too small to cause apparent neurological deficit. ${ }^{22}$ Selected cases, however, have suggested that CMBs can cause neurological symptoms and signs..$^{24,25}$

\section{Prevalence and associated factors for cerebral microbleeds}

\section{Cerebral microbleeds in healthy subjects}

In subjects without a history of cerebrovascular disease, the prevalence of CMBs was reported to be between $3-7 \% .^{26-33}$ Significant associations have been consistently reported between CMBs and advanced age, as well as hypertension. ${ }^{33}$ In contrast, association between CMBs and diabetes has been inconsistent across published reports. ${ }^{19,34,35}$ The Rotterdam Scan Study described CMBs in 1,062 older subjects. ${ }^{39}$ In a group of patients with mean age 69.6 years and a hypertension prevalence of $71.9 \%$, CMBs were detected in $17.8 \%$ of patients aged $60-69$, in $31.3 \%$ of patients aged $70-79$, and in $38.3 \%$ of patients aged 80 97. The prevalence of multiple CMBs was also found to increase significantly with age. ${ }^{37} \mathrm{~A}$ single-hospital-based cross-sectional study performed in Japan found no deep-seated CMBs in subject younger than 40 years old..$^{38}$ The Rotterdam Scan Study also noted a strong association of very low serum cholesterol levels ( $<4.42 \mathrm{mmol} / \mathrm{L}$ versus higher values) with the presence of strictly lobar microbleeds, ${ }^{39}$ an observation consistent with our earlier findings. ${ }^{7}$

\section{Cerebral microbleeds in ischemic stroke patients}

The reported prevalence of CMBs in ischemic stroke patients varies significantly (35\%-71\%; Table 1). 27,38,40-43 This variability may be due to the heterogeneity of ischemic stroke per se, or to differences in recruited populations, rating strategies, and MRI parameters. Two studies investigating CMB frequency in different ischemic stroke subtypes found that CMBs were less frequent in cardioembolic stroke than in atherothrombotic stroke or lacunar stroke. ${ }^{28,44}$ Accumulation of sublethal ischemic injuries in brain parenchyma is thought to differ in atherothrombotic stroke and cardioembolic stroke, ${ }^{45}$ suggesting that the relationship of CMBs and stroke subtype in turn may reflect a different degree of fragility of vascular walls. A recent study found that the absolute number of CMBs, as well as variability indices of blood pressure (including coefficient of variance and successive variation), were elevated in cases of ischemic stroke with CMBs. $^{46}$

Another analysis of patients with ischemic stroke reported that serum uric acid level was associated in a dose-dependent manner with the presence of CMBs, but only in hypertensive patients. ${ }^{47}$ Complex interactions have been observed between chronic medical conditions and individual serologic markers in development of CMBs, such as in ischemic stroke patients with chronic kidney disease. Proteinuria and impaired kidney function has been linked to with small vessel disease in the brain and to CMBs. ${ }^{48-51}$ We further analyzed this issue, and found that chronic kidney disease is independently associated with cerebral microbleeds in patients without diabetes, but not in patients with diabetes. $^{52}$

\section{Cerebral microbleeds in hemorrhagic stroke patients}

The frequency of CMBs in hemorrhagic stroke patients has been consistently higher than that that in ischemic stroke patients, reaching 50\% to $80 \%{ }^{4,8,53-55}$ (Table 2; Figure 3) The detection rate of CMBs is higher in Asian populations, which may reflect a higher prevalence of the hemorrhagic stroke subtype in this ethnic group..$^{56} \mathrm{CMBs}$ also have been reported to be associated with hematoma volume, regardless of perihematomal edema volume. ${ }^{9}$ Patients with cerebral amyloid angiopathy have a higher $\mathrm{CMB}$ detection rate, with a preference for a lobar location, ${ }^{57,58}$ and the presence of the APOE e4 allele also has been reported to favor a lobar location (Figure 4). ${ }^{39,59}$

\section{Longitudinal changes in the number of cerebral microbleeds}

The appearance and disappearance of CMBs over time have not been highlighted sufficiently. In an analysis of 237 acute ischemic stroke patients who underwent follow-up imaging, 
Table 1. Prevalence of cerebral microbleeds in ischemic stroke patients

\begin{tabular}{|c|c|c|c|c|c|}
\hline First author (year) & Patient characteristics & $\begin{array}{l}\text { Cases } \\
\text { number }\end{array}$ & Average age & $\begin{array}{l}\text { Prevalence } \\
(\%)\end{array}$ & Associated findings \\
\hline Kinoshita $(2000)^{27}$ & Multiple lacunar infarcts with hypertension & 68 & $68.8[55-88]$ & 65 & $5 \%$ in non-stroke controls \\
\hline Kato $(2002)^{28}$ & $\begin{array}{l}\text { Ischemic stroke patients with variable time-point } \\
\text { of MR imaging } \\
\text { Atherothrombotic stroke } \\
\text { Cardioembolic stroke } \\
\text { Lacunar stroke }\end{array}$ & $\begin{array}{l}24 \\
23 \\
66\end{array}$ & $\begin{array}{l}74 \pm 10 \\
77 \pm 6 \\
74 \pm 9\end{array}$ & $\begin{array}{l}21 \\
30 \\
62\end{array}$ & $\begin{array}{l}\text { Correlation between number of microbleeds and severity of } \\
\text { white matter hyperintensities }\end{array}$ \\
\hline Tsushima $(2003)^{38}$ & History of ischemic stroke & 232 & NR & 18 & $\begin{array}{l}71 \% \text { in hemorrhagic stroke patients and } 3.7 \% \text { in non-stroke } \\
\text { controls }\end{array}$ \\
\hline Hanyu $(2003)^{30}$ & Multiple lacunar stroke & 51 & $75 \pm 7$ & 51 & $\begin{array}{l}\text { Higher cerebral microbleed (CMB) prevalence in so-called } \\
\text { Binswanger disease }\end{array}$ \\
\hline Fan $(2003)^{10}$ & $\begin{array}{l}\text { Consecutive acute ischemic stroke within } 7 \text { days } \\
\text { after onset }\end{array}$ & 121 & $68 \pm 11$ & 36 & $\begin{array}{l}\text { CMBs as a risk factor of subsequent hemorrhagic stroke in } \\
\text { AIS survivors }\end{array}$ \\
\hline Lee $(2004)^{40}$ & $\begin{array}{l}\text { Consecutive ischemic stroke patients [admitted } \\
\text { 2000-2001] }\end{array}$ & 113 & $65 \pm 9$ & 65 & $\begin{array}{l}\text { CMBs distribution is similar to apparent regional predilection } \\
\text { of intracerebral hemorrhage (ICH) }\end{array}$ \\
\hline Lee $(2004)^{6}$ & $\begin{array}{l}\text { Consecutive acute ischemic stroke patients } \\
\text { [admitted 1998-1999] }\end{array}$ & 144 & $65 \pm 9$ & 35 & Regional association between CMBs and ICH \\
\hline Naka $(2004)^{44}$ & $\begin{array}{l}\text { First ever ischemic stroke patients } \\
\text { Atherothrombotic stroke } \\
\text { Cardioembolic stroke } \\
\text { Lacunar stroke }\end{array}$ & $\begin{array}{l}22 \\
13 \\
31\end{array}$ & $69 \pm 13$ & $\begin{array}{r}23 \\
0 \\
23\end{array}$ & CMBs associated with recurrent stroke and leukoaraiosis \\
\hline Imaizumi $(2004)^{43}$ & Consecutive lacunar infarction patients & 138 & $66 \pm 9$ & 51 & Multiple CMBs ( $\geq 3$ ) associated with recurrent events \\
\hline Schoenwille $(2005)^{81}$ & $\begin{array}{l}\text { Consecutive lacunar infarction patients, within } \\
7 \text { days after onset }\end{array}$ & 68 & NR & 46 & \\
\hline Werring $(2005)^{82}$ & $\begin{array}{l}\text { Consecutive ischemic stroke patients } \\
\text { Consecutive TIA patients }\end{array}$ & $\begin{array}{l}86 \\
43\end{array}$ & $\begin{array}{l}62 \pm 16 \\
67 \pm 9\end{array}$ & $\begin{array}{r}23 \\
2\end{array}$ & \\
\hline Boulanger $(2006)^{69}$ & Ischemic stroke or TIA patients & 236 & & 19 & CMBs associated with subsequent fatal or disabling stroke \\
\hline Ovbiagele $(2006)^{83}$ & $\begin{array}{l}\text { Consecutive ischemic stroke or TIA patients } \\
\text { Large vessel disease } \\
\text { Small vessel disease } \\
\text { Cardioembolism }\end{array}$ & $\begin{array}{r}164 \\
40 \\
44 \\
39\end{array}$ & $\begin{array}{l}78(\mathrm{MB}+), 73 \\
(\mathrm{MB}-)\end{array}$ & $\begin{array}{l}35 \\
18 \\
61 \\
26\end{array}$ & \\
\hline Wardlaw $(2006)^{84}$ & $\begin{array}{l}\text { Patients with mild stroke (partial anterior, lacunar } \\
\text { and posterior circulation syndrome) }\end{array}$ & 241 & 66 [19-89] & 20 & $\begin{array}{l}\text { CMBs associated with the clinicoradiologic syndrome of } \\
\text { lacunar ischemic stroke }\end{array}$ \\
\hline Fiehler $(2007)^{75}$ & $\begin{array}{l}\text { Acute ischemic stroke patients within } 6 \mathrm{~h} \text { after } \\
\text { onset }\end{array}$ & 570 & $\begin{array}{c}69[I \mathrm{QR}, 59 \text { and } \\
77]\end{array}$ & 15 & $\begin{array}{l}\text { No incremental symptomatic ICH after thrombolysis in } \\
\text { presence of CMBs }\end{array}$ \\
\hline Lee $(2008)^{74}$ & $\begin{array}{l}\text { Acute ischemic stroke patients with large artery } \\
\text { atherosclerosis or cardioembolic stroke }\end{array}$ & 377 & $66 \pm 12$ & 29 & $\begin{array}{l}\text { No incremental hemorrhagic transformation in presence } \\
\text { of CMBs }\end{array}$ \\
\hline Seo $(2008)^{85}$ & Acute ischemic stroke or TIA patients & 255 & $64 \pm 12$ & 22 & CMBs associated with pulse wave velocity \\
\hline Cho $(2009)^{51}$ & Consecutive acute ischemic stroke patients & 152 & $67 \pm 12$ & 30 & MBs associated with impaired kidney function \\
\hline Jeon $(2009)^{60}$ & $\begin{array}{l}\text { Consecutive acute ischemic stroke patients } \\
\text { within } 24 \mathrm{hr} \text { after onset }\end{array}$ & 237 & $64 \pm 13$ & 32 & New CMBs after acute ischemic stroke \\
\hline Fiehler (2009) $)^{86}$ & $\begin{array}{l}100 \text { consecutive acute ischemic stroke patients } \\
\text { who received thrombolytic treatment }\end{array}$ & 100 & $62 \pm 13$ & 21 & $\begin{array}{l}\text { Presence of CMB being not associated with post- } \\
\text { thrombolytic parenchymal hematoma }\end{array}$ \\
\hline Staals $(2009)^{87}$ & Lacunar infarct patients & 123 & $65 \pm 12$ & 29 & $\begin{array}{l}\text { High 24-h blood pressure level is associated with the } \\
\text { presence of CMBs }\end{array}$ \\
\hline Ovbiagele $(2010)^{48}$ & Consecutive patients with ischemic stroke or TIA & 236 & 74 (range, 23-100) & 31 & Proteinuria associated with frequency and number of CMBs \\
\hline Ryu $(2012)^{52}$ & Consecutive ischemic stroke patients & 909 & $\begin{array}{l}67 \pm 11(+) \\
64 \pm 12(-)\end{array}$ & 28 & $\begin{array}{l}\text { Chronic kidney disease associated with non-diabetic patients } \\
\text { but not with diabetic patients }\end{array}$ \\
\hline Fluri $(2012)^{88}$ & Consecutive TIA cases & 176 & $69 \pm 13$ & 15 & $\begin{array}{l}\text { Presence of CMBs in TIA patients associated with } \\
\text { subsequent ischemic stroke within } 3 \text { months }\end{array}$ \\
\hline
\end{tabular}

AIS, acute ischemic stroke; TIA, transient ischemic attack; MB, microbleeds; IQR, interquartile range; NR, not reported.

$13 \%$ had new CMBs (56 microbleeds in total) in the subsequent GRE images taken on average after 4 days. ${ }^{60}$ Long-term follow-up also revealed that $23 \%$ of cases demonstrated new CMBs on GRE imaging performed on average over 5.6 years. ${ }^{61}$ Development of new CMBs in this study was associated with high blood pressure and the presence of CMBs on baseline imaging. An additional follow-up study published in 2012 reported that the number of CMBs was increased in $54 \%$ of cases after 2.5 years. $^{62}$ The annual change of CMBs significantly correlated with the number of $\mathrm{CMBs}$ on the baseline study. Another inter- 
Table 2. Prevalence of cerebral microbleeds in hemorrhagic stroke patients

\begin{tabular}{|c|c|c|c|c|c|}
\hline First author (year) & Patients characteristics & $\begin{array}{c}\text { Case } \\
\text { number }\end{array}$ & Age & $\begin{array}{l}\text { Prevalence } \\
(\%)\end{array}$ & Associated findings \\
\hline Tanaka $(1999)^{4}$ & Intracerebral hemorrhage (ICH) patients & 30 & 60 [43-77] & 57 & Providing pathological correlation data \\
\hline $\operatorname{Roob}(2000)^{89}$ & Consecutive primary ICH patients & 109 & $65[22-91]$ & 54 & $\begin{array}{l}\text { Cerebral microbleeds (CMBs) associated with white } \\
\text { matter hyperintensities and lacunar infarctions }\end{array}$ \\
\hline Kinoshita $(2000)^{27}$ & $\begin{array}{l}\text { ICH proved by computed tomography (CT) within } \\
2 \text { days after onset }\end{array}$ & 130 & $64[24-86]$ & 71 & $5 \%$ in non-stroke controls \\
\hline Kato $(2002)^{28}$ & $\begin{array}{l}\text { Hemorrhagic stroke patients with variable } \\
\text { time-point of magnetic resonance imaging (MRI) }\end{array}$ & 35 & $72 \pm 11$ & 71 & $\begin{array}{l}\text { Correlation between number of microbleeds and number } \\
\text { of ICH }\end{array}$ \\
\hline Tsushima $(2003)^{38}$ & History of hemorrhagic stroke & 69 & $63 \pm 10$ & 71 & $\begin{array}{l}\text { Increased distribution of lobar CMBs in lobar ICH patients, } \\
\text { compared to patients with deep ICH }\end{array}$ \\
\hline Jeong $(2004)^{53}$ & Consecutive primary ICH patients & 107 & $62 \pm 13$ & 70 & $\begin{array}{l}\text { CMBs associated with white matter hyperintensities and } \\
\text { lacunar infarcts }\end{array}$ \\
\hline Lee $(2004)^{6}$ & $\begin{array}{l}\text { Consecutive ICH patients with hypertension } \\
\text { [admitted, 2000-2001] }\end{array}$ & 51 & $65 \pm 9$ & 73 & $\begin{array}{l}\text { CMB distribution similar to apparent regional predilection } \\
\text { of ICH }\end{array}$ \\
\hline Lee $(2004)^{8}$ & $\begin{array}{l}\text { Consecutive acute hemorrhagic stroke patients } \\
\text { [admitted 1998-1999] }\end{array}$ & 83 & $66 \pm 11$ & 80 & Regional association between $\mathrm{CMBs}$ and $\mathrm{ICH}$ \\
\hline Greenberg $(2004)^{54}$ & Consecutive primary lobar ICH patients & 94 & $\geq 55$ & 59 & $\begin{array}{l}\text { New CMBs in follow-up imaging associated with recurrent } \\
\text { ICH }\end{array}$ \\
\hline Naka $(2004)^{44}$ & First-ever hemorrhagic stroke patients & 36 & $69 \pm 13$ & 47 & CMBs associated with recurrent stroke and leukoaraiosis \\
\hline Imaizumi (2004) ${ }^{90}$ & Consecutive deep ICH patients & 199 & $66 \pm 11$ & 77 & Multiple CMBs ( $\geq 3$ ) associated with recurrent events \\
\hline Lee $(2005)^{67}$ & $\begin{array}{l}\text { Consecutive primary ICH patients [admitted } \\
\text { 2002-2003] }\end{array}$ & 70 & $70 \pm 10$ & 97 & $\begin{array}{l}\text { CMBs in basal ganglia and thalamus have higher predictive } \\
\text { value for ICH }\end{array}$ \\
\hline Jeon $(2007)^{65}$ & Primary ICH patients with follow-up & 63 & $59 \pm 9$ & 68 & Number of CMBs associated with recurrent ICH \\
\hline $\operatorname{Lim}(2009)^{91}$ & Primary hemorrhagic stroke cases & 234 & $61 \pm 12$ & 80 & \\
\hline Nishikawa $(2009)^{92}$ & Spontaneous ICH cases & 166 & $\begin{array}{l}69 \pm 12(+) \\
64 \pm 11(-)\end{array}$ & 55 & \\
\hline Haussen $(2012)^{93}$ & $\begin{array}{l}\text { Consecutive spontaneous ICH patients with brain } \\
\text { MRI within } 30 \text { days of presentation }\end{array}$ & 176 & $68 \pm 15$ & 52 & Pre-ICH statin use associated with the presence of CMB \\
\hline
\end{tabular}

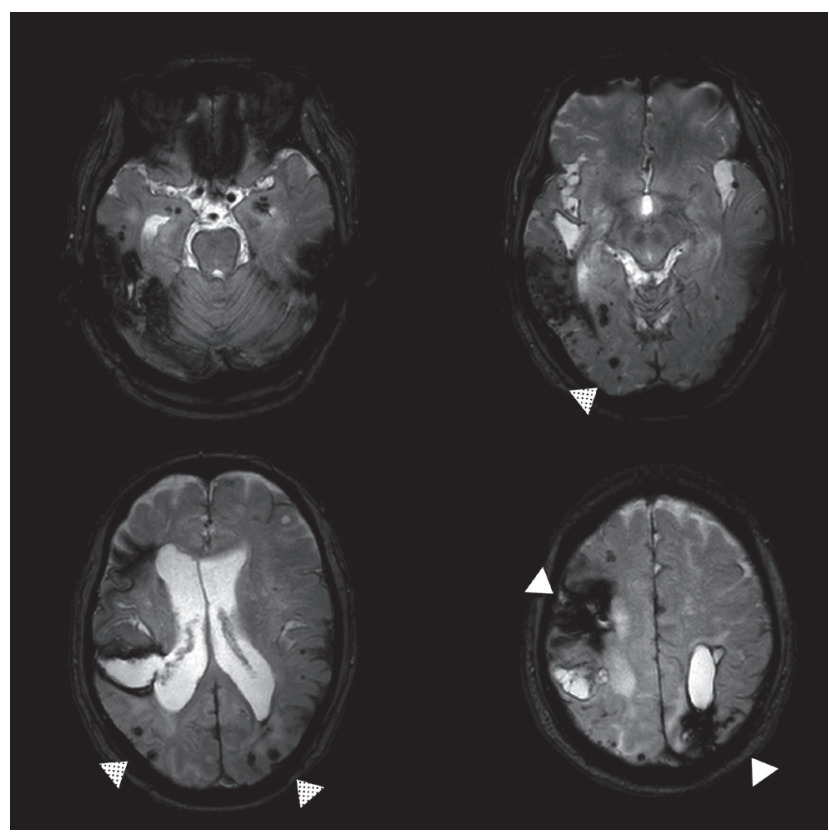

Figure 3. Gradient-echo (GRE) images from a case of multiple lobar hemorrhage (white arrow). Multiple lobar cerebellar microbleeds (CMBs) are visible (dotted arrows). esting finding in that report was that in $15 \%$ of patients, CMBs disappeared on the follow-up GREs. Follow-up analyses of CMBs must be interpreted with caution, however, since spatial registration of baseline and follow-up images has not been performed in any published studies. Use of rigorous rating criteria ${ }^{21}$ is another important factor necessary for detailed evaluation of the natural history of CMBs, including their development and disappearance.

\section{Clinical implications of cerebral microbleeds}

Further understanding of the characteristics of CMBs has generated interest in using detection of $\mathrm{CMBs}$ to enable hemorrhagic stroke risk stratification. A number of reports have described the hemorrhagic tendency of CMBs. ${ }^{24,63,64} \mathrm{~A}$ hemorrhagic transformation after multiple embolic infarctions occurred only in the site of the known CMB. ${ }^{63}$ A Hong Kong study followed 121 acute ischemic stroke patients, and observed that stroke survivors with CMBs on their initial MRI scans had a higher risk of subsequent hemorrhagic stroke. ${ }^{10}$ Hemorrhage counts in initial scans also were found to be pro- 

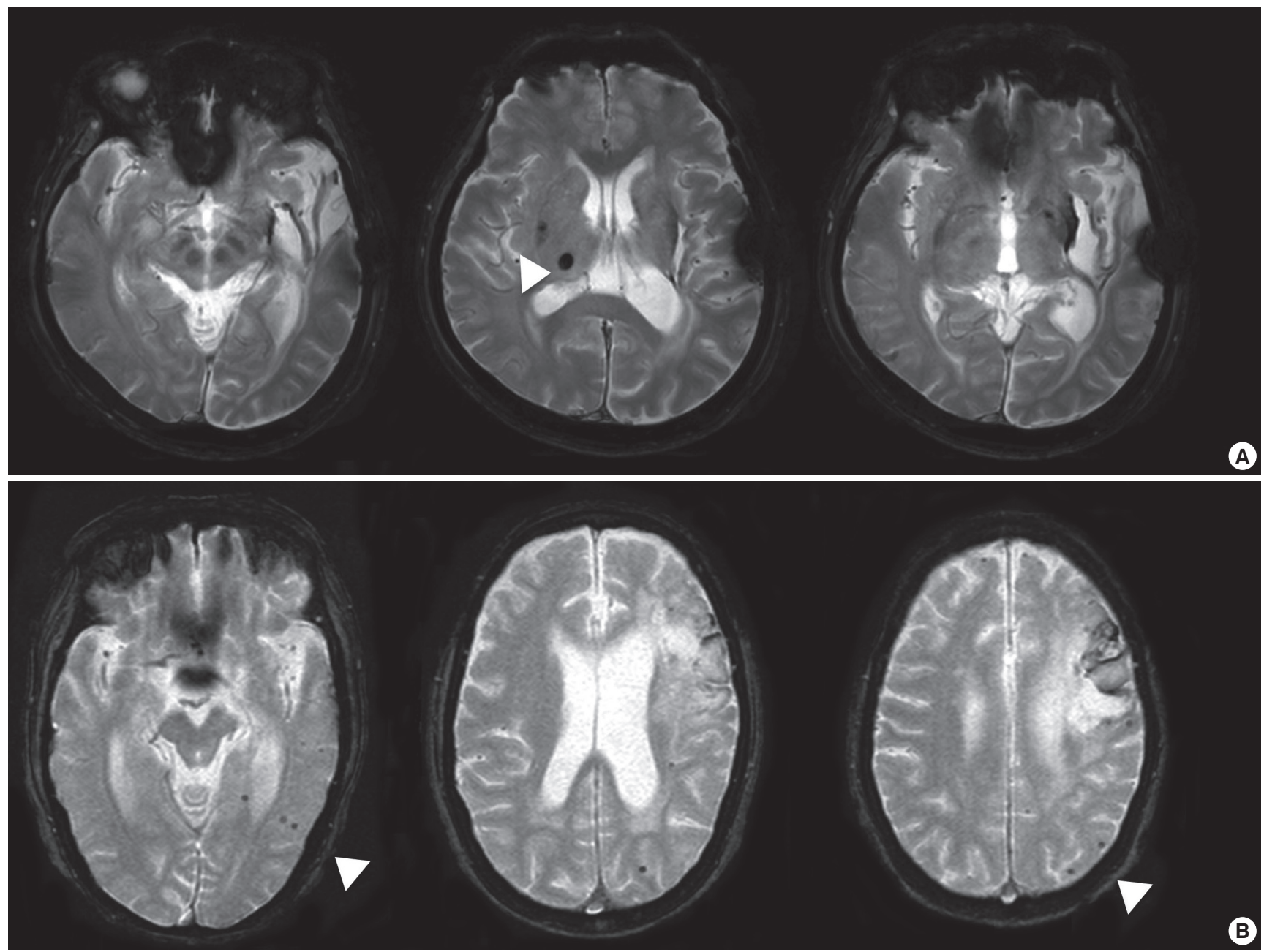

Figure 4. Spatial distribution of cerebral microbleeds by location of hemorrhagic stroke. A case of basal ganglia cerebral hemorrhage with thalamic microbleed (A), compared to a case of lobar hemorrhage with multiple lobar microbleeds (B) in a patient with possible cerebral amyloid angiopathy.

portional to the elevated risk of a future hemorrhagic stroke. ${ }^{54}$ The increased risk of hemorrhagic stroke conferred by the presence of CMBs was also confirmed in a prospective study of 112 ICH survivors. ${ }^{65}$ Furthermore, association between CMBs and larger ICH volume has been suggested by two studies, ${ }^{9,66}$ and the predictive value of $\mathrm{CMBs}$ in $\mathrm{ICH}$ in patients with advanced white matter lesions also has been documented. ${ }^{67}$ The spot sign, an enhancing locus of contrast extravasation in a cerebral hematoma, suggesting ongoing bleeding, was reported to be negatively associated with the number of microbleeds; this result is not consistent with previous findings, and bears further investigation. ${ }^{68}$ Patients with CMBs also have been reported to be 2.8 times more likely to have a subsequent disabling or fatal stroke. $^{69}$ A systematic review published in 2013 concluded that the presence of CMBs in patients with ischemic stroke was associated with greatly increased odds of a subsequent hemorrhagic stroke, but was only modestly linked to recurrence of ischemic stroke. ${ }^{56}$ This meta-analysis also noted that the strength

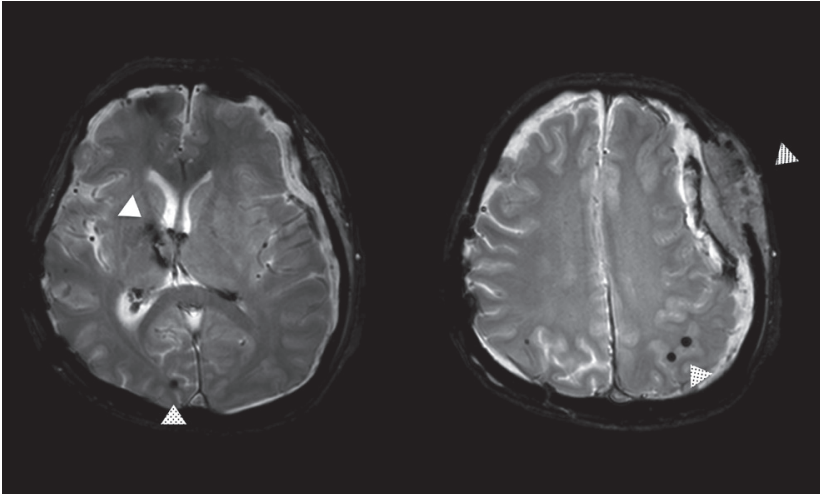

Figure 5. A basal ganglia intracerebral hemorrhage (white arrow) in a patient with a few lobar cerebral microbleeds (dotted arrow). The patient took an antiplatelet medication for several months and developed a subdural hemorrhage (hatched arrow).

of association between $\mathrm{CMBs}$ and subsequent $\mathrm{ICH}$ risk was modified by ethnic background, with a greater odds ratio in Asian cohorts than in Western cohorts (Figure 5). 
The increased likelihood of cerebral hemorrhage associated with the presence of CMBs may allow prediction of hemorrhagic transformation after ischemic stroke. An earlier report suggested that hemorrhagic transformation after thrombolysis was associated with the presence of CMBs. ${ }^{70}$ In a case series of 100 acute ischemic stroke patients with imaging follow-up, the presence of CMBs was indicative of early hemorrhagic transformation. ${ }^{71}$ Embolic ischemic strokes occurring at the sites of previous CMBs were noted to become hemorrhagic. ${ }^{63}$ Contrary to these positive associations, however, a retrospective study of 279 acute ischemic stroke patients reported no association between $\mathrm{CMB}$ count and subsequent hemorrhagic transformation, ${ }^{72}$ and in an analysis of 70 stroke patients on thrombolytic treatment, CMBs failed to predict post-thrombolytic hemorrhagic transformation. ${ }^{73}$ No relationship between CMBs and prediction of hemorrhagic transformation was observed in a group of 1,034 acute ischemic stroke patients recruited in a single hospital. ${ }^{74}$ Finally, a pooled analysis of 570 acute ischemic stroke patients from 13 centers in Europe, North America, and Asia reported that symptomatic $\mathrm{ICH}$ after thrombolytic treatment developed regardless of the initial CMB frequency or extent. $^{75}$ These studies suggest that for patients in need of thrombolysis, any increased risk of $\mathrm{ICH}$ attributable to $\mathrm{CMBs}$ is negligible, and unlikely to exceed the benefits from thrombolytic therapy. A subsequent meta-analysis indicated that the published analyses were vulnerable to publication bias and limited power, and identified a trend toward increased odds of symptomatic hemorrhage after thrombolysis (odds ratio, 1.98; 95\% confidence interval 0.90-4.35). ${ }^{76}$ At present, identification of CMBs on baseline GRE images should not be considered a contraindication to thrombolysis treatment, but further investigation is warranted on this important issue.

Different findings regarding CMBs and the development of $\mathrm{ICH}$ or hemorrhagic transformation may be explained by the different pathological mechanisms of the two phenomena. Essentially, ICH involves rupture of a fragile microvascular wall affected by lipohyalinosis or microaneurysms under the chronic influence of hypertension. ${ }^{77}$ As CMBs have histological characteristics similar to those of vasculopathy, a correspondingly similar mechanism may underlie formation of CMBs and ICHs. ${ }^{22}$ In contrast, hemorrhagic transformation develops after acute lethal injury in relatively healthy microvasculature.

Considerable interest also exists in utilizing detection of CMBs to estimate the risks of hemorrhagic complications in patients on antithrombotic treatment. Two patients on warfarin were reported to have developed lobar hemorrhages right at the location of CMBs. ${ }^{64}$ I CMBs were found to be more frequent and extensive in patients with aspirin-associated $\mathrm{ICH} .{ }^{11,78}$ In a cross- sectional study, CMBs were more common in patients taking antithrombotic agents, and aspirin use was found to be related to a lobar location. ${ }^{79}$ Results from our group demonstrated that patients with anticoagulation-associated hemorrhagic stroke complications are 3.6 times more likely to have CMBs than are age- and sex-matched controls. ${ }^{12}$ A recent pooled analysis involving 1,460 hemorrhagic strokes and 3,817 ischemic strokes concluded that the number of $\mathrm{CMBs}$ was greater in warfarin users who developed ICH. ${ }^{80}$ Given the strong association between $\mathrm{CMBs}$ and subsequent $\mathrm{ICH}$ in stroke survivors, a prospective study is needed to assess the predictive power of CMBs in stroke patients on antithrombotic treatment.

\section{Conclusion}

CMBs were first identified as tiny, round dark-signal lesions on GRE MRI, and are frequently detected in patients with ischemic or hemorrhagic strokes. Pathological analysis demonstrated that $\mathrm{CMBs}$ are extravasations of blood components through fragile microvascular walls, and therefore reflect a bleeding-prone vasculopathy in brain. Several clinical studies have concluded that CMBs are associated with hemorrhagic stroke and hemorrhagic complications following antithrombotic medications. The currently available data do not support the exclusion of thrombolytic treatment based solely on CMB presence or extent. Prospective studies are warranted to confirm the clinical implications of CMBs, and to establish their use for predictive models of hemorrhagic stroke in various situations.

\section{References}

1. Greenberg SM, Vernooij MW, Cordonnier C, Viswanathan A, Al-Shahi Salman R, Warach S, et al. Cerebral microbleeds: a guide to detection and interpretation. Lancet Neurol 2009;8: 165-174.

2. Offenbacher H, Fazekas F, Schmidt R, Koch M, Fazekas G, Kapeller P. MR of cerebral abnormalities concomitant with primary intracerebral hematomas. Am J Neuroradiol 1996;17: 573-578.

3. Werring DJ, Frazer DW, Coward LJ, Losseff NA, Watt H, Cipolotti $\mathrm{L}$, et al. Cognitive dysfunction in patients with cerebral microbleeds on T2*-weighted gradient-echo MRI. Brain 2004; 127:2265-2275

4. Tanaka A, Ueno Y, Nakayama Y, Takano K, Takebayashi S. Small chronic hemorrhages and ischemic lesions in association with spontaneous intracerebral hematomas. Stroke 1999;30:16371642.

5. Fazekas F, Kleinert R, Roob G, Kleinert G, Kapeller P, Schmidt 
$\mathrm{R}$, et al. Histopathologic analysis of foci of signal loss on gradient-echo T2*-weighted MR images in patients with spontaneous intracerebral hemorrhage: evidence of microangiopathyrelated microbleeds. Am J Neuroradiol 1999;20:637-642.

6. Lee SH, Park JM, Kwon SJ, Kim H, Kim YH, Roh JK, et al. Left ventricular hypertrophy is associated with cerebral microbleeds in hypertensive patients. Neurology 2004;63:16-21.

7. Lee SH, Bae HJ, Yoon BW, Kim H, Kim DE, Roh JK. Low Concentration of Serum Total Cholesterol Is Associated With Multifocal Signal Loss Lesions on Gradient-Echo Magnetic Resonance Imaging: Analysis of Risk Factors for Multifocal Signal Loss Lesions. Stroke 2002;33:2845-2849.

8. Lee SH, Bae HJ, Kwon SJ, Kim H, Kim YH, Yoon BW, et al. Cerebral microbleeds are regionally associated with intracerebral hemorrhage. Neurology 2004;62:72-76.

9. Lee SH, Kim BJ, Roh JK. Silent microbleeds are associated with volume of primary intracerebral hemorrhage. Neurology 2006;66:430-432.

10. Fan YH, Zhang L, Lam WWM, Mok VCT, Wong KS. Cerebral microbleeds as a risk factor for subsequent intracerebral hemorrhages among patients with acute ischemic stroke. Stroke 2003; 34:2459-2462.

11. Wong KS, Chan YL, Liu JY, Gao S, Lam WWM. Asymptomatic microbleeds as a risk factor for aspirin-associated intracerebral hemorrhages. Neurology 2003;60:511-513.

12. Lee SH, Ryu WS, Roh JK. Cerebral microbleeds are a risk factor for warfarin-related intracerebral hemorrhage. Neurology 2009;72:171-176.

13. Atlas SW, Mark AS, Grossman RI, Gomori JM. Intracranial hemorrhage: gradient-echo MR imaging at $1.5 \mathrm{~T}$. Comparison with spin-echo imaging and clinical applications. Radiology 1988; 168:803-807.

14. Reichenbach JR, Jonetz-Mentzel L, Fitzek C, Haacke EM, Kido DK, Lee BC, et al. High-resolution blood oxygen-level dependent MR venography (HRBV): a new technique. Neuroradiology 2001;43:364-369.

15. Reichenbach JR, Venkatesan R, Schillinger DJ, Kido DK, Haacke EM. Small vessels in the human brain: MR venography with deoxyhemoglobin as an intrinsic contrast agent. Radiology 1997; 204:272-277.

16. Haacke EM, Xu Y, Cheng Y-CN, Reichenbach JR. Susceptibility weighted imaging (SWI). Magn Reson Med 2004;52:612618.

17. Ayaz M, Boikov AS, Haacke EM, Kido DK, Kirsch WM. Imaging cerebral microbleeds using susceptibility weighted imaging: one step toward detecting vascular dementia. J Magn Reson Imaging 2010;31:142-148.

18. Stehling C, Wersching H, Kloska SP, Kirchhof P, Ring J, Nas- senstein I, et al. Detection of asymptomatic cerebral microbleeds: a comparative study at 1.5 and 3.0 T. Acad Radiol 2008;15:895900.

19. Cordonnier C, Al-Shahi Salman R, Wardlaw J. Spontaneous brain microbleeds: systematic review, subgroup analyses and standards for study design and reporting. Brain 2007;130:19882003.

20. Greenberg SM, Nandigam RNK, Delgado P, Betensky RA, Rosand J, Viswanathan A, et al. Microbleeds versus macrobleeds: evidence for distinct entities. Stroke 2009;40:2382-2386.

21. Gregoire SM, Chaudhary UJ, Brown MM, Yousry TA, Kallis $\mathrm{C}$, ger HRJ, et al. The Microbleed Anatomical Rating Scale (MARS): reliability of a tool to map brain microbleeds. Neurology 2009; 73:1759-1766.

22. Fisher M, French S, Ji P, Kim RC. Cerebral microbleeds in the elderly: a pathological analysis. Stroke 2010;41:2782-2785.

23. Schrag M, McAuley G, Pomakian J, Jiffry A, Tung S, Mueller $\mathrm{C}$, et al. Correlation of hypointensities in susceptibility-weighted images to tissue histology in dementia patients with cerebral amyloid angiopathy: a postmortem MRI study. Acta Neuropathol 2010;119:291-302.

24. Kim YS, Lee J, Baek W, Lee YJ, Kim HY. Pontine hemorrhage at a microbleed site in a patient with central pontine myelinolysis. Neurol Sci 2011;32:1251-1252.

25. Simonsen CZ, Nielsen E. Hypertensive microbleed as a transient ischemic attack mimic. Case Rep Neurol 2013;5:31-33.

26. Roob G, Schmidt R, Kapeller P, Lechner A, Hartung HP, Fazekas F. MRI evidence of past cerebral microbleeds in a healthy elderly population. Neurology 1999;52:991-994.

27. Kinoshita T, Okudera T, Tamura H, Ogawa T, Hatazawa J. Assessment of Lacunar Hemorrhage Associated With Hypertensive Stroke by Echo-Planar Gradient-Echo T2*-Weighted MRI. Stroke 2000;31:1646-1650.

28. Kato H, Izumiyama M, Izumiyama $K$, Takahashi $A$, Itoyama $Y$. Silent cerebral microbleeds on T2*-weighted MRI: correlation with stroke subtype, stroke recurrence, and leukoaraiosis. Stroke 2002;33:1536-1540.

29. Tsushima Y, Tanizaki Y, Aoki J, Endo K. MR detection of microhemorrhages in neurologically healthy adults. Neuroradiology 2002;44:31-36.

30. Hanyu H, Tanaka Y, Shimizu S, Takasaki M, Fujita H, Kaneko $\mathrm{N}$, et al. Cerebral microbleeds in Binswanger\&apos;s disease: a gradient-echo $\mathrm{T} 2{ }^{*}$-weighted magnetic resonance imaging study. Neurosci Lett 2003;340:213-216.

31. Jeerakathil T, Wolf PA, Beiser A, Hald JK, Au R, Kase CS, et al. Cerebral microbleeds: prevalence and associations with cardiovascular risk factors in the Framingham Study. Stroke 2004;35: 1831-1835. 
32. Igase M, Tabara Y, Igase K, Nagai T, Ochi N, Kido T, et al. Asymptomatic cerebral microbleeds seen in healthy subjects have a strong association with asymptomatic lacunar infarction. Circ J2009;73:530-533.

33. Poels MMF, Vernooij MW, Ikram MA, Hofman A, Krestin GP, van der Lugt A, et al. Prevalence and risk factors of cerebral microbleeds: an update of the Rotterdam scan study. Stroke 2010; 41:S103-106.

34. Kim BJ, Lee SH, Kang BS, Yoon B-W, Roh J-K. Diabetes increases large artery diseases, but not small artery diseases in the brain. JNeurol 2008;255:1176-1181.

35. Naka H, Nomura E, Kitamura J, Imamura E, Wakabayashi S, Matsumoto M. Antiplatelet Therapy as a Risk Factor for Microbleeds in Intracerebral Hemorrhage Patients: Analysis Using Specific Antiplatelet Agents. J Stroke Cerebrovasc Dis 2012.

36. Vernooij MW, van der Lugt A, Breteler MMB. Risk of thrombolysis-related hemorrhage associated with microbleed presence. Stroke 2008;39:e115.

37. Poels MMF, Ikram MA, van der Lugt A, Hofman A, Krestin $\mathrm{GP}$, Breteler MMB, et al. Incidence of cerebral microbleeds in the general population: the Rotterdam Scan Study. Stroke 2011; 42:656-661.

38. Tsushima Y, Aoki J, Endo K. Brain Microhemorrhages Detected on T2*-Weighted Gradient-Echo MR Images. Am J Neuroradiol 2003;24:88-96.

39. Vernooij MW, van der Lugt A, Ikram MA, Wielopolski PA, Niessen WJ, Hofman A, et al. Prevalence and risk factors of cerebral microbleeds: the Rotterdam Scan Study. Neurology 2008; 70:1208-1214.

40. Lee SH, Kwon SJ, Kim KS, Yoon BW, Roh J-K. Cerebral microbleeds in patients with hypertensive stroke. Topographical distribution in the supratentorial area. J Neurol 2004;251:11831189.

41. Lee SH, Bae HJ, Ko S-B, Kim H, Yoon BW, Roh JK. Comparative analysis of the spatial distribution and severity of cerebral microbleeds and old lacunes. J Neurol Neurosurg Psychiatry 2004; 75:423-427.

42. Lee SH, Kwon SJ, Kim KS, Yoon BW, Roh J-K. Topographical distribution of pontocerebellar microbleeds. Am J Neuroradiol 2004;25:1337-1341.

43. Imaizumi T, Horita Y, Chiba M, Hashimoto Y, Honma T, Niwa J. Dot-like hemosiderin spots on gradient echo $\mathrm{T} 2{ }^{*}$-weighted magnetic resonance imaging are associated with past history of small vessel disease in patients with intracerebral hemorrhage. J Neuroimaging 2004;14:251-257.

44. Naka H, Nomura E, Wakabayashi S, Kajikawa H, Kohriyama T, Mimori Y, et al. Frequency of asymptomatic microbleeds on $\mathrm{T} 2 *$-weighted MR images of patients with recurrent stroke: as- sociation with combination of stroke subtypes and leukoaraiosis. Am J Neuroradiol 2004;25:714-719.

45. Kim BJ, Lee SH, Ryu WS, Kang BS, Kim CK, Yoon BW. Low Level of Low-Density Lipoprotein Cholesterol Increases Hemorrhagic Transformation in Large Artery Atherothrombosis but Not in Cardioembolism. Stroke 2009;40:1627-1632.

46. Liu W, Liu R, Sun W, Peng Q, Zhang W, Xu E, et al. Different impacts of blood pressure variability on the progression of cerebral microbleeds and white matter lesions. Stroke 2012;43: 2916-2922.

47. Ryu WS, Kim CK, Kim BJ, Lee SH. Serum Uric Acid Levels and Cerebral Microbleeds in Patients with Acute Ischemic Stroke. PLoS ONE 2013;8:e55210.

48. Ovbiagele B, Liebeskind DS, Pineda S, Saver JL. Strong independent correlation of proteinuria with cerebral microbleeds in patients with stroke and transient ischemic attack. Arch Neurol 2010;67:45-50.

49. Ikram MA, Vernooij MW, Hofman A, Niessen WJ, van der Lugt A, Breteler MMB. Kidney function is related to cerebral small vessel disease. Stroke 2008;39:55-61.

50. Khatri M, Wright CB, Nickolas TL, Yoshita M, Paik MC, Kranwinkel $\mathrm{G}$, et al. Chronic kidney disease is associated with white matter hyperintensity volume: the Northern Manhattan Study (NOMAS). Stroke 2007;38:3121-3126.

51. Cho AH, Lee SB, Han SJ, Shon YM, Yang DW, Kim BS. Impaired kidney function and cerebral microbleeds in patients with acute ischemic stroke. Neurology 2009;73:1645-1648.

52. Ryu WS, Lee S-H, Kim CK, Kim BJ, Yoon BW. The relation between chronic kidney disease and cerebral microbleeds: difference between patients with and without diabetes. Int J Stroke 2012;7:551-557.

53. Jeong SW, Jung KH, Chu K, Bae HJ, Lee SH, Roh JK. Clinical and radiologic differences between primary intracerebral hemorrhage with and without microbleeds on gradient-echo magnetic resonance images. Arch Neurol 2004;61:905-909.

54. Greenberg SM, Eng JA, Ning M, Smith EE, Rosand J. Hemorrhage Burden Predicts Recurrent Intracerebral Hemorrhage After Lobar Hemorrhage. Stroke 2004;35:1415-1420.

55. Imaizumi T, Honma T, Horita Y, Kawamura M, Kohama I, Miyata $\mathrm{K}$, et al. The number of microbleeds on gradient $\mathrm{T} 2{ }^{*}$-weighted magnetic resonance image at the onset of intracerebral hemorrhage. J Stroke Cerebrovasc Dis 2008; 17:30-34.

56. Charidimou A, Kakar P, Fox Z, Werring DJ. Cerebral microbleeds and recurrent stroke risk: systematic review and metaanalysis of prospective ischemic stroke and transient ischemic attack cohorts. Stroke 2013;44:995-1001.

57. Lee SH, Kim SM, Kim N, Yoon BW, Roh JK. Cortico-subcortical distribution of microbleeds is different between hyperten- 
sion and cerebral amyloid angiopathy. J Neurol Sci 2007;258: 111-114.

58. Rosand J, Muzikansky A, Kumar A, Wisco JJ, Smith EE, Betensky RA, et al. Spatial clustering of hemorrhages in probable cerebral amyloid angiopathy. Ann Neurol 2005;58:459-462.

59. Kim M, Bae HJ, Lee J, Kang L, Lee S, Kim S, et al. APOE epsilon2/epsilon4 polymorphism and cerebral microbleeds on gradient-echo MRI. Neurology 2005;65:1474-1475.

60. Jeon SB, Kwon SU, Cho AH, Yun SC, Kim JS, Kang DW. Rapid appearance of new cerebral microbleeds after acute ischemic stroke. Neurology 2009;73:1638-1644.

61. Gregoire SM, Brown MM, Kallis C, Jäger HR, Yousry TA, Werring DJ. MRI detection of new microbleeds in patients with ischemic stroke: five-year cohort follow-up study. Stroke 2010; 41:184-186.

62. Lee SH, Lee ST, Kim BJ, Park HK, Kim CK, Jung KH, et al. Dynamic Temporal Change of Cerebral Microbleeds: LongTerm Follow-Up MRI Study. PLoS ONE 2011;6:e25930.

63. Kim BJ, Lee S-H. Silent microbleeds and hemorrhagic conversion of an embolic infarction. J Clin Neurol 2007;3:147-149.

64. Lee GH, Kwon SU, Kang DW. Warfarin-induced intracerebral hemorrhage associated with microbleeds. J Clin Neurol 2008;4: 131-133.

65. Jeon SB, Kang DW, Cho AH, Lee EM, Choi CG, Kwon SU, et al. Initial microbleeds at MR imaging can predict recurrent intracerebral hemorrhage. J Neurol 2007;254:508-512.

66. Imaizumi T, Honma T, Horita Y, Kohama I, Miyata K, Kawamura $\mathrm{M}$, et al. Hematoma size in deep intracerebral hemorrhage and its correlation with dot-like hemosiderin spots on gradient echo T2*-weighted MRI. J Neuroimaging 2006;16:236-242.

67. Lee SH, Heo JH, Yoon BW. Effects of microbleeds on hemorrhage development in leukoaraiosis patients. Hypertens Res 2005;28:895-899.

68. Evans A, Demchuk A, Symons SP, Dowlatshahi D, Gladstone $\mathrm{DJ}$, Zhang $\mathrm{L}$, et al. The spot sign is more common in the absence of multiple prior microbleeds. Stroke 2010;41:2210-2217.

69. Boulanger JM, Coutts SB, Eliasziw M, Gagnon AJ, Simon JE, Subramaniam $S$, et al. Cerebral microhemorrhages predict new disabling or fatal strokes in patients with acute ischemic stroke or transient ischemic attack. Stroke 2006;37:911-914.

70. Kidwell CS, Saver JL, Villablanca JP, Duckwiler G, Fredieu A, Gough $\mathrm{K}$, et al. Magnetic resonance imaging detection of microbleeds before thrombolysis: an emerging application. Stroke 2002;33:95-98.

71. Nighoghossian N, Hermier M, Adeleine P, Blanc-Lasserre K, Derex L, Honnorat J, et al. Old microbleeds are a potential risk factor for cerebral bleeding after ischemic stroke: a gradient-echo T2*-weighted brain MRI study. Stroke 2002;33:735-742.
72. Kim HS, Lee DH, Ryu CW, Lee JH, Choi CG, Kim SJ, et al. Multiple cerebral microbleeds in hyperacute ischemic stroke: impact on prevalence and severity of early hemorrhagic transformation after thrombolytic treatment. Am J Roentgenol 2006; 186:1443-1449.

73. Kakuda W, Thijs VN, Lansberg MG, Bammer R, Wechsler L, Kemp S, et al. Clinical importance of microbleeds in patients receiving IV thrombolysis. Neurology 2005;65:1175-1178.

74. Lee SH, Kang BS, Kim N, Roh JK. Does microbleed predict haemorrhagic transformation after acute atherothrombotic or cardioembolic stroke? J Neurol Neurosurg Psychiatry 2008;79: 913-916.

75. Fiehler J, Albers GW, Boulanger JM, Derex L, Gass A, Hjort N, et al. Bleeding risk analysis in stroke imaging before thromboLysis (BRASIL): pooled analysis of T2*-weighted magnetic resonance imaging data from 570 patients. Stroke 2007 ;38:27382744.

76. Shoamanesh A, Kwok CS, Lim PA, Benavente OR. Postthrombolysis intracranial hemorrhage risk of cerebral microbleeds in acute stroke patients: a systematic review and meta-analysis. Int J Stroke 2013;8:348-356.

77. Xi G, Keep RF, Hoff JT. Mechanisms of brain injury after intracerebral haemorrhage. The Lancet Neurology 2006;5:53-63.

78. Wong KS, Mok V, Lam WWM, Kay R, Tang A, Chan YL, et al. Aspirin-associated intracerebral hemorrhage: Clinical and radiologic features. Neurology 2000;54:2298-2301.

79. Vernooij MW, Haag MDM, van der Lugt A, Hofman A, Krestin GP, Stricker BH, et al. Use of antithrombotic drugs and the presence of cerebral microbleeds: the Rotterdam Scan Study. Arch Neurol 2009;66:714-720.

80. Lovelock CE, Cordonnier C, Naka H, Al-Shahi Salman R, Sudlow CLM, Group TESS, et al. Antithrombotic Drug Use, Cerebral Microbleeds, and Intracerebral Hemorrhage: A Systematic Review of Published and Unpublished Studies. Stroke 2010; 41:1222-1228.

81. Schonewille WJ, Singer MB, Atlas SW, Tuhrim S. The prevalence of microhemorrhage on gradient-echo magnetic resonance imaging in acute lacunar infarction. J Stroke Cerebrovasc Dis 2005; 14:141-144.

82. Werring DJ, Coward LJ, Losseff NA, Jäger HR, Brown MM. Cerebral microbleeds are common in ischemic stroke but rare in TIA. Neurology 2005;65:1914-1918.

83. Ovbiagele B, Saver JL, Sanossian N, Salamon N, Villablanca P, Alger JR, et al. Predictors of cerebral microbleeds in acute ischemic stroke and TIA patients. Cerebrovasc Dis 2006;22:378383.

84. Wardlaw JM, Lewis SC, Keir SL, Dennis MS, Shenkin S. Cerebral microbleeds are associated with lacunar stroke defined 
clinically and radiologically, independently of white matter lesions. Stroke 2006;37:2633-2636.

85. Seo WK, Lee JM, Park MH, Park KW, Lee DH. Cerebral microbleeds are independently associated with arterial stiffness in stroke patients. Cerebrovasc Dis 2008;26:618-623.

86. Fiehler J, Siemonsen S, Thomalla G, Illies T, Kucinski T. Combination of T2* W and FLAIR abnormalities for the prediction of parenchymal hematoma following thrombolytic therapy in 100 stroke patients. J Neuroimaging 2009;19:311-316.

87. Staals J, van Oostenbrugge RJ, Knottnerus IL, Rouhl RP, Henskens LH, Lodder J. Brain microbleeds relate to higher ambulatory blood pressure levels in first-ever lacunar stroke patients. Stroke 2009;40:3264-3268.

88. Fluri F, Jax F, Amort M, Wetzel SG, Lyrer PA, Katan M, et al. Significance of microbleeds in patients with transient ischaemic attack. Eur J Neurol 2012;19:522-524.

89. Roob G, Lechner A, Schmidt R, Flooh E, Hartung HP, Faze- kas F. Frequency and location of microbleeds in patients with primary intracerebral hemorrhage. Stroke 2000;31:2665-2669.

90. Imaizumi T, Horita Y, Hashimoto Y, Niwa J. Dotlike hemosiderin spots on $\mathrm{T} 2{ }^{*}$-weighted magnetic resonance imaging as a predictor of stroke recurrence: a prospective study. J Neurosurg 2004;101:915-920.

91. Lim JB, Kim E. Silent microbleeds and old hematomas in spontaneous cerebral hemorrhages. J Korean Neurosurg Soc 2009; 46:38-44.

92. Nishikawa T, Ueba T, Kajiwara M, Fujisawa I, Miyamatsu N, Yamashita K. Cerebral microbleeds predict first-ever symptomatic cerebrovascular events. Clin Neurol Neurosurg 2009;111: 825-828.

93. Haussen DC, Henninger N, Kumar S, Selim M. Statin use and microbleeds in patients with spontaneous intracerebral hemorrhage. Stroke 2012;43:2677-2681. 